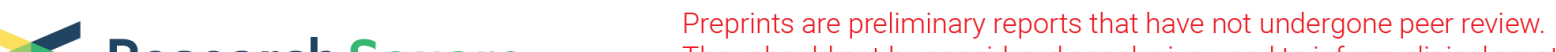 Research Square They should not be considered conclusive, used to inform clinical practice, or referenced by the media as validated information.
}

\section{Mechanical Ventilation with Dynamic Compliance- Guided Positive End-Expiratory Pressure in Laparoscopic Surgery with Trendelenburg Positioning: A Eandomised Controlled Study}

\section{Yun Wang}

Shanghai General Hospital, Shanghai Jiao Tong University (LC) and Nanjing Medical University (SL) Huijuan Wang

Shanghai General Hospital, Shanghai Jiao Tong University (LC) and Nanjing Medical University (SL)

Xiaoli Wang

Shanghai General Hospital, Shanghai Jiao Tong University (LC) and Nanjing Medical University (SL)

Hong Wang

Shanghai General Hospital, Shanghai Jiao Tong University (LC) and Nanjing Medical University (SL)

Shitong Li

Shanghai General Hospital, Shanghai Jiao Tong University (LC) and Nanjing Medical University (SL) Lianhua Chen ( $\sim$ spinny8898@sina.com )

Shanghai General Hospital, Shanghai Jiao Tong University (LC) and Nanjing Medical University (SL)

\section{Research Article}

Keywords: positive end-expiratory pressure, pulmonary dynamic compliance, mechanical ventilation, right heart function, transoesophageal echocardiography

Posted Date: December 29th, 2021

DOI: https://doi.org/10.21203/rs.3.rs-1150866/v1

License: (c) (i) This work is licensed under a Creative Commons Attribution 4.0 International License. Read Full License 


\section{Abstract}

BACKGROUND: The intraoperative cardiorespiratory effect of ventilation with individualised positive endexpiratory pressure guided by dynamic compliance (Cdyn) remains undefined. We investigated whether individualised protective ventilation would protect the heart and lung more efficiently than standard protective ventilation during abdominal laparoscopic surgery with Trendelenburg positioning.

METHODS: Forty patients undergoing abdominal laparoscopic surgery were randomly divided into two groups: Group T (titrimetric PEEP) and Group I (intentional PEEP, $5 \mathrm{cmH}_{2} \mathrm{O}$ ).

Parameters of right ventricular function were measured via transoesophageal echocardiography, including tricuspid annular plane systolic excursion (TAPSE), early filling-to-late filling ratio of the right ventricle, and right ventricular end-diastolic area/left ventricular end-diastolic area (RVEDA/LVEDA) ratio. Cdyn, driving pressure $(\Delta \mathrm{P})$, ratio of dead space to tidal volume (VD/VT), and partial pressure of arterial oxygen to inspiratory oxygen fraction (PF) ratio were measured during mechanical ventilation.

RESULTS: The RVEDA/LVEDA ratio in all patients increased significantly at $T_{2}$ compared with $T_{0}$, but there were no significant differences in TAPSE or E/A ratio between groups during the whole procedure $(P>0.05)$. Cdyn, $\Delta P$, and VD/VT ratios in Group $T$ were significantly improved compared to those in Group $I$ at $T_{2}(P<0.05)$. There was no significant difference in the $P F$ ratio between groups $(P>0.05)$.

CONCLUSIONS: Intraoperative lung-protective ventilation with Cdyn-guided PEEP improved Cdyn, $\Delta \mathrm{P}$, and VD/VT ratio without obvious side effects on right ventricular function compared to standard protective ventilation during laparoscopic surgery with Trendelenburg positioning, which suggests that it is a circulation-friendly way to titrate PEEP for intraoperative lung protective ventilation.

\section{TRIAL REGISTRATION:}

Trial registration date: 13/09/2020;

Trial registration number: ChiCTR2000038212.

\section{Background}

Pulmonary ventilation can be further impaired by the application of mechanical ventilation, pneumoperitoneum (PNP), and position during laparoscopic abdominal surgery.[1-3] Mechanical ventilation that combines low tidal volume and recruitment manoeuvres with an individualised positive end-expiratory pressure (PEEP) has demonstrated favourable lung-protective effects in patients with previously normal lung function.[4-9] However, the optimal PEEP level varies among individuals and surgical types. An inadequately high level of positive airway pressure has the potential to distend nondependent lung areas[10] and impair cardiac performance.[11-14] The latter can manifest as reduced cardiac output and acute cor pulmonale.[15] 
Alternatively, protective ventilation, in which the PEEP level is tailored to the respiratory system's dynamic compliance (Cdyn) after a recruitment manoeuvre, has resulted in favourable physiological effects when used intraoperatively. $[8,16]$ However, the actual influence of individualised PEEP on circulation in patients during laparoscopic abdominal surgery remains unclear.

Based on the above, we hypothesised that protective ventilation with Cdyn-guided PEEP would protect cardiopulmonary function more efficiently than standard protective ventilation with intentional PEEP (5 $\mathrm{cmH}_{2} \mathrm{O}$ ) during laparoscopic abdominal surgery in the Trendelenburg position.

\section{Methods}

\section{Ethics, consent, and permission}

The study was registered on 13/09/2020(ChiCTR2000038212) on chictr.org.cn, and was approved by the Medical Ethics Committee of Shanghai General Hospital with approval number [No. 202036]. All research procedures adhered to the CONSORT guidelines, and written informed consent was obtained from all patients. All methods were carried out in accordance with Declaration of Helsinki

\section{Study design and patient population}

The study included consecutive patients with American Society of Anesthesiologists physical status I-II who underwent elective laparoscopic abdominal surgery, including rectal or colon resection. The exclusion criteria were as follows: age $<20$ years or $>65$ years; obesity $\left(>28 \mathrm{~kg} / \mathrm{m}^{2}\right)$; previous known respiratory or cardiovascular disease; or throat, oesophageal, or any other disorders that may affect transoesophageal echocardiography (TEE).

\section{Randomisation and masking}

This was a randomised controlled study. Randomisation was carried by a computer-generated allocation sequence. Participants were divided into two groups ( $n=20 /$ group). People who had access to the randomisation information were not involved in any experimental trial procedure.

The patients were blinded to the treatment allocation. Intraoperative data were collected by an unblinded investigator. TEE measurements were performed and recorded using a multiplane 5-MHz and an echocardiographic device (Vivid 7 Dimension; GE Vingmed Ultrasound AS, Horten, Norway). All measurements were performed by the same examiner who was blinded to the allocation and were recorded on video. The saved results were reviewed postoperatively by two experienced echocardiographers who were not involved in the study.

\section{Anaesthesia management}

The duration of preoperative fasting was 8-10 h. Upon arrival in the operating room, patients received 5 $\mathrm{mL} / \mathrm{kg}$ Ringer's lactate solution. The fluid treatment was continued at $5 \mathrm{~mL} / \mathrm{kg} / \mathrm{h}$ during surgery. 
[17] Electrocardiogram (ECG), heart rate (HR), non-invasive blood pressure, end-tidal $\mathrm{CO}_{2}$ pressure, peripheral oxygen saturation, and bispectral index (EEG VISTA monitor, Covidien, Boulder, CO) were measured. Arterial blood samples were collected to assess partial pressures of $\mathrm{CO}_{2}$ and $\mathrm{O}_{2}\left(\mathrm{PaCO}_{2}\right.$ and $\mathrm{PaO}_{2}$, respectively).

Anaesthesia was induced with midazolam (1-2 mg), sufentanyl (0.2-0.4 $\mu \mathrm{g} / \mathrm{kg})$, propofol (1.5-2.5 mg/kg), and rocuronium (0.6-1 $\mathrm{mg} / \mathrm{kg}$ ), and maintained with sevoflurane (0.8-1.0 minimum alveolar concentration) and remifentanil $(0.5 \mu \mathrm{g} / \mathrm{kg} / \mathrm{h})$. Sufficient levels of muscle relaxation and analgesia during surgery were achieved using increments of rocuronium $(0.2 \mathrm{mg} / \mathrm{kg})$ according to the twitch monitor (Innervator, Fisher \& Paykel, Laguna Hills, CA).

\section{Ventilation settings and study protocol}

Pre-oxygenation was performed for 5 min at a fraction of inspired oxygen $\left(\mathrm{FiO}_{2}\right)$ of 1.0 with a tightly sealed face mask. The lungs were ventilated after a recruitment manoeuvre of $40 \mathrm{cmH}_{2} \mathrm{O}$ continuous positive airway pressure applied for $30 \mathrm{~s}$ by hand bagging with $\mathrm{FiO}_{2}$ of $60 \%$ in a volume-controlled mode. The tidal volume (VT) was $6-8 \mathrm{~mL} / \mathrm{kg}$ of ideal body weight calculated as $50+0.91 \times$ (height [cm] - 152.4) for men and $45.5+0.91 \times$ (height [cm] - 152.4) for women [18] and VT and respiratory rate were adjusted to maintain peak inspiratory pressure (PIP) below $35 \mathrm{cmH}_{2} \mathrm{O}$ and end-expiratory $\mathrm{PaCO}_{2}\left(\mathrm{PetCO}_{2}\right)$ between 35 and $45 \mathrm{mmHg}$ throughout the procedure. After intubation, a TEE probe was inserted into the oesophagus.

Patients were changed to a steep Trendelenburg position after PNP was induced. The intra-abdominal pressure (IAP) was maintained up to $12 \mathrm{mmHg}$ (UHI-4, Olympus Medical Systems, Tokyo, Japan). After the second recruitment manoeuvre, the PEEP increment trial was initiated in the study group (Group T) with steps of $2 \mathrm{cmH}_{2} \mathrm{O}$ from $5 \mathrm{cmH}_{2} \mathrm{O}$ until the maximal Cdyn was obtained. Volume-controlled ventilation and individualised PEEP levels were then established after the third recruitment manoeuvre and maintained throughout the study period. In the control group, the same procedures were followed, except for PEEP titration; PEEP was set at a fixed level of $5 \mathrm{cmH}_{2} \mathrm{O}$ (Fig. 1).

\section{Measurements}

An S/5 monitor (GE Healthcare, Chicago, IL) was used to monitor the mean arterial pressure, $\mathrm{HR}, \mathrm{PetCO}_{2}$, VT, RR, PIP, and plateau inspiratory pressure continuously. The gas sampling tube using the side-stream technique to record Cdyn was connected to the respiratory circuit. Arterial blood samples were collected for blood gas analysis to record arterial $\mathrm{PaCO}_{2}$ and arterial $\mathrm{PaO}_{2}$. Each measurement was obtained and recorded at three time points including: immediately after anaesthesia induction $\left(T_{0}\right), 5$ min after PNP and Trendelenburg positioning $\left(T_{1}\right)$, and 30 min after mechanical ventilation with $\operatorname{PEEP}\left(T_{2}\right)$.

Tricuspid annular plane systolic excursion (TAPSE) was measured using the M-mode from a standard apical four-chamber view centred on the right ventricle (RV). The cursor was aligned parallel to the 
longitudinal displacement of the tricuspid valve plane with the RV free wall carefully. Electronic callipers were used to calculate the displacement between the most basilar position of the tricuspid annulus at end-diastole and at end-systole with the leading-edge method (Fig. 2A).

A four-chamber view was used to measure the RV end-diastolic area (RVEDA) and the left ventricular (LV) end-diastolic area (LVEDA) by tracing the endocardium in the end-diastole period. The RVEDA/LVEDA ratio was calculated from these values (Fig. 2B).

Pulsed-wave Doppler ultrasonography was used to measure the ratio of the tricuspid peak velocity of early filling (E) to the peak velocity of late filling (A) (E/A ratio) by scanning from the apical four-chamber view with the sample volume positioned at the valvular leaflet tips (Fig. $2 \mathrm{C}$ ).

All measurements were performed on five consecutive beats during sinus rhythm.

Other derived variables were calculated according to the following equations:

$\Delta \mathrm{P}=\mathrm{P}_{\text {plat }}-\mathrm{PEEP} ;[19]$

VD/VT $=1.14 \times\left(\mathrm{PaCO}_{2}-\mathrm{PetCO}_{2}\right) / \mathrm{PaCO}_{2}-0.005,[20]$ where VD is dead space; and

$\mathrm{PF}=\mathrm{PaO}_{2} / \mathrm{FiO}_{2}[21]$

\section{Statistical analysis}

No studies to date have specifically studied parameters of RV function in relation to changes in PEEP during laparoscopic abdominal surgery. We calculated from a pilot study that 18 participants in each group would be sufficient to identify a difference of 0.4 in TAPSE between individualised and intentional PEEP groups with $a$ and $\beta$ errors of 0.05 and 0.2 , respectively, with a power of 0.8 using PASS software (version 11.0.7, NCSS, Kaysville, UT). Considering the potential loss to follow-up and missing data, the sample size of each group was increased to 20 .

Numbers with percentages in parentheses are used to present categorical data. Continuous data are presented as mean \pm standard deviation; otherwise, medians with interquartile ranges are used.

Statistical analyses were performed using Prism 8.0 (GraphPad Software, San Diego, CA). We used the Kolmogorov-Smirnov test to verify the normality of data. Comparisons between groups or different timepoints were performed using two-way repeated-measures analysis of variance, and comparisons of categorical variables between groups were performed using the chi-squared test. A $P$ value less than 0.05 was accepted as statistically significant.

\section{Results}

\section{Patient characteristics}


Fifty-three patients were recruited; nine refused to participate and four were excluded due to failure to insert the TEE probe in time. We studied 40 patients, all of whom completed the protocol successfully without complications (Fig. 3). The demographics and clinical data are presented in Table 1. There were no significant differences in hemodynamic measurements between the groups at any timepoint (Table 2).

\section{Right ventricular parameters}

During the study, there was no change in the TAPSE or E/A ratio of the RV $(P>0.05)$ (Fig. 4A, 4C). The RVEDA/LVEDA ratio increased significantly at $\mathrm{T}_{2}$ compared with $\mathrm{T}_{0}$ in both groups (Group I, $P=0.0018$; Group T, $P=0.0208$ ) (Table 3, Fig. 4B).

\section{Pulmonary parameters}

After the PEEP increment trial, the optimal Cdyn-guided PEEP for Group T reached an average of $7.88 \mathrm{cmH}_{2} \mathrm{O}$ (Table 3).

The Cdyn decreased significantly from $\mathrm{T}_{0}$ to $\mathrm{T}_{1}(P<0.001)$ without a difference between the groups $(P>$ 0.05). After recruitment manoeuvre and ventilation with different PEEP, improvements in Cdyn were obtained in both groups at $\mathrm{T}_{2}$ compared to $\mathrm{T}_{1}(P<0.001)$ (Table 3$)$, and Group T had a significantly higher Cdyn than Group I $(P=0.029)$ (Fig. 5D).

There were significant increases in the $\triangle \mathrm{P}$ and VD/VT ratio in both groups at T1 compared to T0 in all patients $(\mathrm{P}<0.001)$. There were increases in VD/VT and $\triangle \mathrm{P}$ in Group I after ventilation with PEEP $\left(P_{\Delta \mathrm{P}}<\right.$ $\left.0.001 ; P_{\text {VD } / \text { VT ratio }}=0.019\right)$ (Table 3). However, the $\Delta \mathrm{P}$ and VD/VT ratio of Group T dropped, with no significant differences compared to T0 $(P>0.05)$, (Table 3). At T2, the $\triangle \mathrm{P}$ and VD/VT ratio differed between groups $\left(P_{\triangle \mathrm{P}}<0.001 ; P_{\mathrm{VD} / \mathrm{VT} \text { ratio }}=0.002\right)$ (Fig. 5E, 5F).

However, no significant changes in the PF ratio were found $(P>0.05)$ (Table 3, Fig. 5G).

\section{Discussion}

This is the first clinical study to investigate whether mechanical ventilation affects right heart function assessed by TEE in healthy patients undergoing laparoscopic abdominal surgery with Trendelenburg positioning randomised to Cdyn-guided PEEP or fixed PEEP. Our study suggests that Cdyn-guided PEEP mechanical ventilation was sufficient to maintain the normal intraoperative systolic and diastolic function of the RV, resulting in better Cdyn, lower VD/VT, and driving pressure compared to standard lungprotective mechanical ventilation.

PNP induced before laparoscopic surgery by insufflating $\mathrm{CO}_{2}$ into the abdomen together with the special surgical position are known to affect both the respiratory and cardiac systems.[22] Rist et al.[23] conducted an observational trial in patients in the lithotomy position during lower abdominal laparoscopic surgery. They found that RV function deteriorated because of PNP and position changes. In 
our study, the RVEDA/LVEDA ratio was chosen to evaluate right heart function because it can provide information about combined systolic and diastolic function,[24] and about preload and afterload independently in non-acute conditions.[25] Our results showed that all enrolled patients experienced an increase in the RVEDA/LVEDA ratio at $30 \mathrm{~min}$ after mechanical ventilation, suggesting that significant myocardial dysfunction was found with fixed PEEP but not with individualised PEEP.

Ventilation strategies, including PEEP at an appropriate level, can reduce pulmonary vascular resistance and enhance the washout of expiratory $\mathrm{CO}_{2}$. Russo et al.[22] concluded that PEEP can improve cardiac function in laparoscopic surgery. Bernard et al.[26] demonstrated that suitable PEEP can provide a moderate elevation of intrathoracic pressure, which may prevent vessel collapse and restore the pressure gradient between the intrathoracic and intra-abdominal compartments. In other words, PEEP may act as a shield against the negative cardiopulmonary effects induced by PNP. However, it is not easy to find a "balanced" PEEP between cardiac function and pulmonary function. An arbitrary decision usually made by clinicians to set a higher level of PEEP aiming for an "open lung" may contribute to overdistension and haemodynamic instability.[27] Decreased cardiac output during PEEP is mediated by increased intrathoracic pressure and a reduction in venous return, because of decreased RV preload and increased RV afterload.[28-31] Severe depression of cardiovascular function appears to be critical in patients who are treated with high PEEP and require haemodynamic support.[12]. A multicentre randomised controlled trial suggested that the use of a high level of PEEP and recruitment manoeuvres does not reduce the incidence of postoperative pulmonary complications and more frequently results in unwanted haemodynamic side effects.[32] In our study, we employed dynamic compliance to guide intraoperative PEEP selection. Cdyn appeared to be superior in determining the "ideal" PEEP because of its holistic response to heart-lung reactions. Cdyn, when shown as "slope" or "flexibility" in a pressure-volume curve, has a single-peak type of relation with PEEP, indicating that adverse effects of PEEP were clearly evident when Cdyn deteriorated.[33] In our results, RV systolic and diastolic functions, as expressed by TAPSE and the $E / A$ ratio obtained from $T E E$, were not significantly affected by gas insufflation or position change. Cdyn-guided PEEP ventilation ameliorated RV systolic function compared to fixed PEEP ventilation at $30 \mathrm{~min}$ after PEEP according to the TAPSE normality threshold of greater than $1.7 \mathrm{~mm}$.[34] Therefore, Cdyn-guided PEEP ventilation seemed to be sufficient to maintain the normal function of the $\mathrm{RV}$ by offsetting the effects of an augmented IAP on pulmonary vascular resistance.

On the other hand, ventilation strategies including PEEP are conventionally recommended to mitigate the respiratory effects of PNP.[35] The lung-protective effects of PEEP are established by the increase in the dependent lung areas, the reduction of atelectasis and re-expansion, and the improvement of gas exchange. Similar to the result from electrical impedance tomography-guided PEEP (7.88 vs. $\left.8 \mathrm{cmH}_{2} \mathrm{O}\right)$, [10] our results also showed that Cdyn-guided PEEP could improve ventilation in patients undergoing laparoscopic surgery.

The main limitations of our study are the relatively small number of patients involved the and short-term follow-up. Similarly, we set $\mathrm{FiO}_{2}$ at 0.6 during the surgery. $\mathrm{An} \mathrm{FiO}_{2}$ of 0.6 was adequate to maintain the intraoperative oxygen supply and consumption balance and to avoid the potential deleterious effects of 
hypoxia. However, a recent systematic review revealed that arterial hyperoxia maybe associated with poor hospital outcomes.[36] Therefore, more convincing data are needed to provide tailored concentration of oxygen to expand upon our study.

\section{Conclusions}

This is the first published study attempting to compare the cardiopulmonary effect of Cdyn-guided PEEP and fixed PEEP together with low VT and recruitment manoeuvres in patients with good functional status undergoing abdominal laparoscopic surgery in the Trendelenburg position. Cdyn-guided PEEP was also sufficient to maintain the normal systolic and diastolic function of the RV, and led to better Cdyn, lower driving pressure, and a better VD/VT ratio. Based on these results, we recommend consideration of Cdynguided PEEP together with low tidal volume and recruitment manoeuvres as the cardiopulmonaryprotective ventilation of choice for patients undergoing the abdominal laparoscopic surgery in the Trendelenburg position.

\section{Declarations}

Ethics approval and consent to participate: This study was approved by the Medical Ethics Committee of Shanghai General Hospital (No. 202036). Written informed consent was obtained from all patients.

Consent for publication: Not applicable

Availability of data and materials:Not available before 2025

Competing interests: The authors declare that they have no competing interests.

Funding: No funding. .

Authors' contributions: YW, HW, and SL conceived of and designed the study. LC and SL provided administrative support. YW and HW collected the data. All authors were involved in data analysis, interpretation, and manuscript writing.

Acknowledgments: The authors gratefully acknowledge the cooperation of the staff of the Department of Anesthesiology at Shanghai General Hospital and the sonographers in the Department of Ultrasonography at Shanghai General Hospital.

\section{References}

1. Bendixen HH, Hedley-Whyte J, Laver MB: Impaired Oxygenation in Surgical Patients during General Anesthesia with Controlled Ventilation. A Concept of Atelectasis. N Engl J Med 1963, 269:991-996.

2. Valenza F, Chevallard G, Fossali T, Salice V, Pizzocri M, Gattinoni L: Management of mechanical ventilation during laparoscopic surgery. Best Pract Res Clin Anaesthesiol 2010, 24(2):227-241. 
3. Andersson LE, Baath M, Thorne A, Aspelin P, Odeberg-Wernerman S: Effect of carbon dioxide pneumoperitoneum on development of atelectasis during anesthesia, examined by spiral computed tomography. Anesthesiology 2005, 102(2):293-299.

4. Tusman G, Bohm SH, Suarez-Sipmann F, Turchetto E: Alveolar recruitment improves ventilatory efficiency of the lungs during anesthesia. Can J Anaesth 2004, 51(7):723-727.

5. Tusman G, Bohm SH, Sipmann FS, Maisch S: Lung recruitment improves the efficiency of ventilation and gas exchange during one-lung ventilation anesthesia. Anesth Analg 2004, 98(6):1604-1609, table of contents.

6. Tusman G, Groisman I, Fiolo FE, Scandurra A, Arca JM, Krumrick G, Bohm SH, Sipmann FS: Noninvasive monitoring of lung recruitment maneuvers in morbidly obese patients: the role of pulse oximetry and volumetric capnography. Anesth Analg 2014, 118(1):137-144.

7. Maisch S, Reissmann H, Fuellekrug B, Weismann D, Rutkowski T, Tusman G, Bohm SH: Compliance and dead space fraction indicate an optimal level of positive end-expiratory pressure after recruitment in anesthetized patients. Anesth Analg 2008, 106(1):175-181, table of contents.

8. Ferrando C, Mugarra A, Gutierrez A, Carbonell JA, Garcia M, Soro M, Tusman G, Belda FJ: Setting individualized positive end-expiratory pressure level with a positive end-expiratory pressure decrement trial after a recruitment maneuver improves oxygenation and lung mechanics during onelung ventilation. Anesth Analg 2014, 118(3):657-665.

9. Jabaudon M, Futier E, Roszyk L, Sapin V, Pereira B, Constantin JM: Association between intraoperative ventilator settings and plasma levels of soluble receptor for advanced glycation endproducts in patients without preexisting lung injury. Respirology 2015, 20(7):1131-1138.

10. He X, Jiang J, Liu Y, Xu H, Zhou S, Yang S, Shi X, Yuan H: Electrical Impedance Tomography-guided PEEP Titration in Patients Undergoing Laparoscopic Abdominal Surgery. Medicine (Baltimore) 2016, 95(14):e3306.

11. Dantzker DR, Lynch JP, Weg JG: Depression of cardiac output is a mechanism of shunt reduction in the therapy of acute respiratory failure. Chest 1980, 77(5):636-642.

12. Jardin F, Farcot JC, Boisante L, Curien N, Margairaz A, Bourdarias JP: Influence of positive endexpiratory pressure on left ventricular performance. N Engl J Med 1981, 304(7):387-392.

13. Biondi JW, Schulman DS, Soufer R, Matthay RA, Hines RL, Kay HR, Barash PG: The effect of incremental positive end-expiratory pressure on right ventricular hemodynamics and ejection fraction. Anesth Analg 1988, 67(2):144-151.

14. Pinsky MR, Desmet JM, Vincent JL: Effect of positive end-expiratory pressure on right ventricular function in humans. Am Rev Respir Dis 1992, 146(3):681-687.

15. Boissier F, Katsahian S, Razazi K, Thille AW, Roche-Campo F, Leon R, Vivier E, Brochard L, VieillardBaron A, Brun-Buisson $\mathrm{C}$ et al: Prevalence and prognosis of cor pulmonale during protective ventilation for acute respiratory distress syndrome. Intensive Care Med 2013, 39(10):1725-1733.

16. Ferrando C, Suarez-Sipmann F, Tusman G, Leon I, Romero E, Gracia E, Mugarra A, Arocas B, Pozo N, Soro $\mathrm{M}$ et al: Open lung approach versus standard protective strategies: Effects on driving pressure 
and ventilatory efficiency during anesthesia - A pilot, randomized controlled trial. PLoS One 2017, 12(5): $\mathrm{e} 0177399$.

17. Gan TJ, Soppitt A, Maroof M, el-Moalem H, Robertson KM, Moretti E, Dwane P, Glass PS: Goaldirected intraoperative fluid administration reduces length of hospital stay after major surgery. Anesthesiology 2002, 97(4):820-826.

18. Linares-Perdomo O, East TD, Brower R, Morris AH: Standardizing Predicted Body Weight Equations for Mechanical Ventilation Tidal Volume Settings. Chest 2015, 148(1):73-78.

19. Amato MB, Meade MO, Slutsky AS, Brochard L, Costa EL, Schoenfeld DA, Stewart TE, Briel M, Talmor $\mathrm{D}$, Mercat $\mathrm{A}$ et al: Driving pressure and survival in the acute respiratory distress syndrome. $\mathrm{N} \mathrm{Engl} \mathrm{J}$ Med 2015, 372(8):747-755.

20. Hardman JG, Aitkenhead AR: Estimating alveolar dead space from the arterial to end-tidal CO(2) gradient: a modeling analysis. Anesth Analg 2003, 97(6):1846-1851.

21. Ferrando C, Soro M, Unzueta C, Suarez-Sipmann F, Canet J, Librero J, Pozo N, Peiro S, Llombart A, Leon I et al: Individualised perioperative open-lung approach versus standard protective ventilation in abdominal surgery (iPROVE): a randomised controlled trial. Lancet Respir Med 2018, 6(3):193-203.

22. Russo A, Di Stasio E, Scagliusi A, Bevilacqua F, Isgro MA, Marana R, Marana E: Positive endexpiratory pressure during laparoscopy: cardiac and respiratory effects. J Clin Anesth 2013, 25(4):314-320.

23. Rist M, Hemmerling TM, Rauh R, Siebzehnrubl E, Jacobi KE: Influence of pneumoperitoneum and patient positioning on preload and splanchnic blood volume in laparoscopic surgery of the lower abdomen. J Clin Anesth 2001, 13(4):244-249.

24. Karatzis EN, Giannakopoulou AT, Papadakis JE, Karazachos AV, Nearchou NS: Myocardial performance index (Tei index): evaluating its application to myocardial infarction. Hellenic $J$ Cardiol 2009, 50(1):60-65.

25. Haddad F, Hunt SA, Rosenthal DN, Murphy DJ: Right ventricular function in cardiovascular disease, part I: Anatomy, physiology, aging, and functional assessment of the right ventricle. Circulation 2008, 117(11):1436-1448.

26. Bernard D, Brandely A, Scatton O, Schoeffler P, Futier E, Lescot T, Beaussier M: Positive end-expiratory pressure does not decrease cardiac output during laparoscopic liver surgery: A prospective observational evaluation. HPB (Oxford) 2017, 19(1):36-41.

27. Suter PM, Fairley B, Isenberg MD: Optimum end-expiratory airway pressure in patients with acute pulmonary failure. N Engl J Med 1975, 292(6):284-289.

28. Cournand A, Motley HL: Physiological studies of the effects of intermittent positive pressure breathing on cardiac output in man. Am J Physiol 1948, 152(1):162-174.

29. Terai C, Uenishi M, Sugimoto H, Shimazu T, Yoshioka T, Sugimoto T: Transesophageal echocardiographic dimensional analysis of four cardiac chambers during positive end-expiratory pressure. Anesthesiology 1985, 63(6):640-646. 
30. Huemer G, Kolev N, Kurz A, Zimpfer M: Influence of positive end-expiratory pressure on right and left ventricular performance assessed by Doppler two-dimensional echocardiography. Chest 1994, 106(1):67-73.

31. Kang WS, Kim SH, Kim SY, Oh CS, Lee SA, Kim JS: The influence of positive end-expiratory pressure on stroke volume variation in patients undergoing cardiac surgery: an observational study. $J$ Thorac Cardiovasc Surg 2014, 148(6):3139-3145.

32. Anaesthesiology PNIftCTNotESo, Hemmes SN, Gama de Abreu M, Pelosi P, Schultz MJ: High versus low positive end-expiratory pressure during general anaesthesia for open abdominal surgery (PROVHILO trial): a multicentre randomised controlled trial. Lancet 2014, 384(9942):495-503.

33. Kallet RH: Should PEEP Titration Be Based on Chest Mechanics in Patients With ARDS? Respir Care 2016, 61(6):876-890.

34. Tamborini G, Pepi M, Galli CA, Maltagliati A, Celeste F, Muratori M, Rezvanieh S, Veglia F: Feasibility and accuracy of a routine echocardiographic assessment of right ventricular function. Int $\mathrm{J}$ Cardiol 2007, 115(1):86-89.

35. Loring SH, Behazin N, Novero A, Novack V, Jones SB, O'Donnell CR, Talmor DS: Respiratory mechanical effects of surgical pneumoperitoneum in humans. $J$ Appl Physiol (1985) 2014, 117(9):1074-1079.

36. Helmerhorst HJ, Roos-Blom MJ, van Westerloo DJ, de Jonge E: Association Between Arterial Hyperoxia and Outcome in Subsets of Critical IIlness: A Systematic Review, Meta-Analysis, and MetaRegression of Cohort Studies. Crit Care Med 2015, 43(7):1508-1519.

\section{Tables}

Table.1. Baseline characteristics of the patients $(n=40)$ 


\begin{tabular}{|c|c|c|}
\hline Characteristics and clinical data & Group I & Group T \\
\hline Age (yr), mean (SD) & $49 \pm 12$ & $51 \pm 10$ \\
\hline Male, n (\%) & $10(50)$ & $11(55)$ \\
\hline $\mathrm{BMI}\left(\mathrm{kg} \cdot \mathrm{m}^{-2}\right)$, mean (SD) & $23.8 \pm 2.8$ & $24.2 \pm 3.1$ \\
\hline LAP rectectomy, n (\%) & $9(45)$ & $9(45)$ \\
\hline LAP colectomy, n (\%) & $11(55)$ & $11(55)$ \\
\hline Pneumoperitoneum duration (min), mean (SD) & $119 \pm 21$ & $117 \pm 20$ \\
\hline Operative time (min), mean (SD) & $143 \pm 25$ & $148 \pm 21$ \\
\hline Lactated Ringer's solution (ml), mean (SD) & $1405 \pm 265$ & $1435 \pm 242$ \\
\hline Urinary output (ml), mean (SD) & $130 \pm 20$ & $125 \pm 25$ \\
\hline Blood loss(ml), median (IQR) & $60(20,150)$ & $65(20,150)$ \\
\hline \multicolumn{3}{|l|}{ Use of vasoactive drugs, $n$ (\%) } \\
\hline Ephedrine, n (\%) & $3(15)$ & $4(20)$ \\
\hline Dose $\left(\mathrm{mg} \cdot \mathrm{kg}^{-1}\right)$, median (IQR) & $0.10(0.10-0.33)$ & $0.15(0.09-0.33)$ \\
\hline Sinus rhythm, n (\%) & $20(100)$ & $20(100)$ \\
\hline
\end{tabular}

Data are given as the mean (SD) when normally distributed, otherwise the median with interquartile ranges is used. Numbers are presented with $n(\%)$. Group I, control group $\left(P E E P=5 \mathrm{cmH}_{2} \mathrm{O}\right)$; Group T, Cdynguided PEEP. BMI, body mass index, weight $(\mathrm{kg}) \cdot$ height $^{-2}(\mathrm{~m})$; LAP, Laparoscopic; IQR, interquartile range.

Table. 2. Intraoperative hemodynamic characteristics $(n=40)$

\begin{tabular}{|lllll|}
\hline \multirow{2}{*}{ Group I } & Measurements & T0 & T1 & T2 \\
\cline { 2 - 5 } & MAP (mmHg), mean (SD) & $83.9 \pm 10.5$ & $85.3 \pm 10.1$ & $82.2 \pm 11.2$ \\
\cline { 2 - 5 } Group T & MAP (bpm), mean (SD) & $63.8 \pm 9.9$ & $66.6 \pm 9.6$ & $65.0 \pm 8.8$ \\
\cline { 2 - 5 } & HR (bpm), mean (SD) & $65.8 \pm \pm 10.6$ & $67.6 \pm 9.2$ & $69.3 \pm 9.0$ \\
\hline
\end{tabular}

Data are given as the mean $\pm S D$ when normally distributed, otherwise the median with interquartile ranges is used. Numbers are presented with $n(\%)$. Group I, control group $\left(P E E P=5 \mathrm{cmH}_{2} \mathrm{O}\right)$; Group T, Cdyn-guided PEEP. T0, 15min after intubation. T1, 15min after pneumoperitoneum and position change; T2, 30min after ventilation with different PEEP. MAP, mean arterial pressure; $H R$, heart rate. 
Table. 3. Intraoperative respiratory and right heart function characteristics $(n=40)$

\begin{tabular}{|c|c|c|c|c|}
\hline & Parameters & T0 & T1 & $\mathrm{T} 2$ \\
\hline \multirow[t]{8}{*}{ Group I } & Cdyn $\left(\mathrm{ml} / \mathrm{cmH}_{2} \mathrm{O}\right)$ & $49.12 \pm 10.98$ & $27.96 \pm 8.26^{*}$ & $32.40 \pm 8.43^{\star \dagger}$ \\
\hline & Driving pressure $\left(\mathrm{cmH}_{2} \mathrm{O}\right)$ & $13.08 \pm 2.14$ & $19.88 \pm 2.76^{\star}$ & $17.76 \pm 2.65^{\star \dagger}$ \\
\hline & VD/VT(\%) & $10.80 \pm 4.51$ & $19.52 \pm 4.22^{*}$ & $24.04 \pm 4.53^{\star \dagger}$ \\
\hline & $\mathrm{PF}(\mathrm{mmHg})$ & $461.60 \pm 65.99$ & $430.64 \pm 115.36$ & $454.36 \pm 115.36$ \\
\hline & TAPSE (cm) & $1.55 \pm 0.32$ & $1.63 \pm 0.28$ & $1.50 \pm 0.39$ \\
\hline & RVEDA/LVEDA & $0.54 \pm 0.01$ & $0.56 \pm 0.02$ & $0.62 \pm 0.06^{*}$ \\
\hline & $\mathrm{E} / \mathrm{A}$ & $1.45 \pm 0.12$ & $1.51 \pm 0.13$ & $1.34 \pm 0.38$ \\
\hline & PEEP $\left(\mathrm{cmH}_{2} \mathrm{O}\right)$ & $0 \pm 0$ & $0 \pm 0$ & $5.00 \pm 0.00$ \\
\hline \multirow[t]{8}{*}{ Group T } & Cdyn $\left(\mathrm{ml} / \mathrm{cmH}_{2} \mathrm{O}\right)$ & $49.84 \pm 10.88$ & $27.56 \pm 4.86^{*}$ & $36.04 \pm 6.67^{\star+} \S$ \\
\hline & Driving pressure $\left(\mathrm{cmH}_{2} \mathrm{O}\right)$ & $13.04 \pm 2.34$ & $19.68 \pm 4.04^{*}$ & $13.76 \pm 2.86^{\# \S}$ \\
\hline & VD/VT(\%) & $11.80 \pm 8.12$ & $20.14 \pm 7.16^{*}$ & $18.16 \pm 6.68^{\star} \S$ \\
\hline & $\mathrm{PF}(\mathrm{mmHg})$ & $471.40 \pm 126.15$ & $427.36 \pm 114.71$ & $443.32 \pm 98.58$ \\
\hline & TAPSE $(\mathrm{cm})$ & $1.55 \pm 0.42$ & $1.75 \pm 0.42$ & $1.84 \pm 0.35$ \\
\hline & RVEDA/LVEDA & $0.53 \pm 0.02$ & $0.57 \pm 0.02$ & $0.60 \pm 0.06^{*}$ \\
\hline & $\mathrm{E} / \mathrm{A}$ & $1.44 \pm 0.17$ & $1.45 \pm 0.11$ & $1.60 \pm 0.55$ \\
\hline & PEEP $\left(\mathrm{cmH}_{2} \mathrm{O}\right)$ & $0 \pm 0$ & $0 \pm 0$ & $7.88 \pm 1.54$ \\
\hline
\end{tabular}

Data are given as the mean (SD). Group I, control group $\left(\mathrm{PEEP}=5 \mathrm{cmH}_{2} \mathrm{O}\right)$; Group T, Cdyn-guided PEEP. T0, $15 \mathrm{~min}$ after intubation. $\mathrm{T} 1,15 \mathrm{~min}$ after pneumoperitoneum and position change; T2, 30min after ventilation with different PEEP. ${ }^{*}, \mathrm{P}<0.05$ as compared to T0 within the group; ${ }^{\dagger}, \mathrm{P}<0.05$ as compared to T1 within the group; §, $\mathrm{P}<0.05$ as compared to Group I at T2. Cdyn, dynamic compliance; VD/VT, dead space; PF, partial pressure of arterial oxygen to inspiratory oxygen fraction; TAPSE, tricuspid annular plane systolic excursion; RVEDA/LVEDA, right ventricular end-diastolic area to left ventricular enddiastolic area ratio; $\mathrm{E} / \mathrm{A}$, peak velocity of early filling to peak velocity of late filling ratio of right ventricle; PEEP, positive end-expiratory pressure.

\section{Figures}




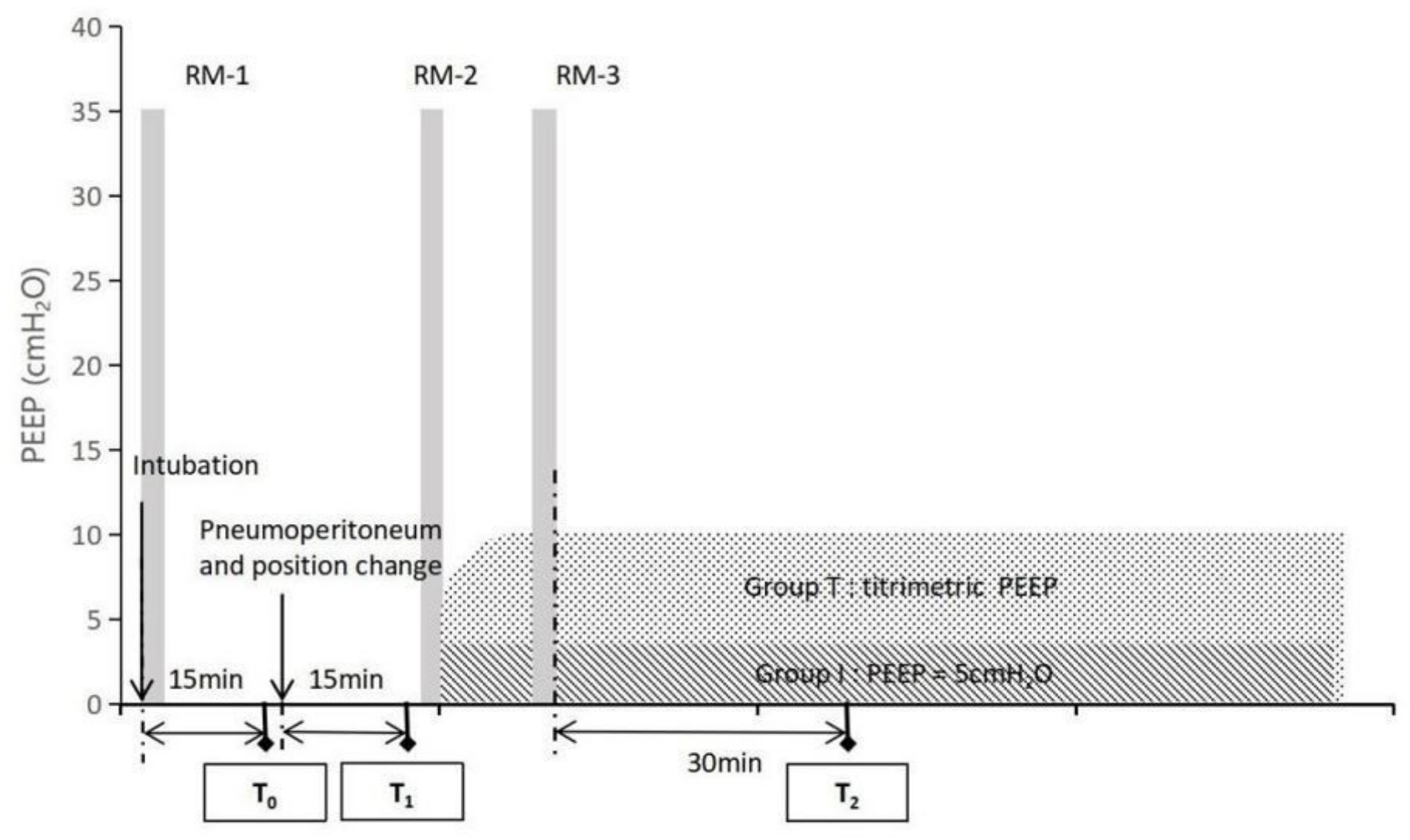

\section{Figure 1}

PEEP titration. $T_{0}, 15 \mathrm{~min}$ after intubation; $T_{1}, 15 \mathrm{~min}$ after pneumoperitoneum and position change; $\mathrm{T}_{2}$, 30 min after ventilation with different PEEP. PEEP, positive end-expiratory pressure. 

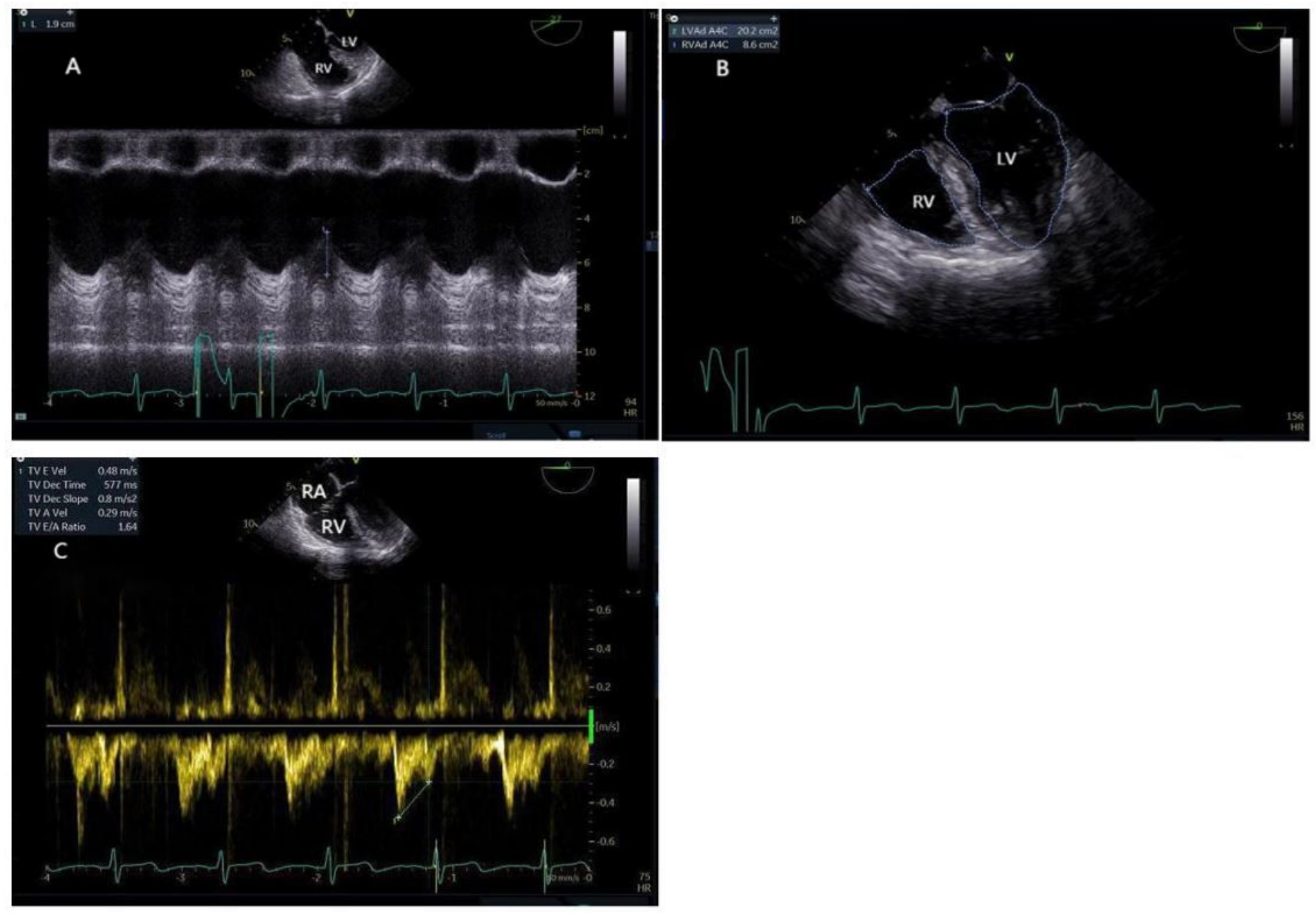

Figure 2

A Tricuspid annular plane systolic excursion (TAPSE) 30min after ventilation with PEEP. TAPSE was measured by 2-dimensional echocardiography-guided M-mode recordings from theapical 4-chamber view, with the cursor placed at the free wall of the tricuspid annulus. Maximal TAPSE was determined by the total excursion of the tricuspid annulus from its highest position after atrial ascent to the lowest point of descent during ventricular systole. RV, right ventricle; LV, left ventricle.

B Right ventricular end-diastolic area/left ventricular end-diastolic area (RVEDA/LVEDA) ratio 30min after ventilation with PEEP. RVEDA/LVEDA ratio were measured by tracing the RV and LV endocardium in the 4chamber view. RV, right ventricle; LV, left ventricle.

C Peak velocity of early filling $(E)$ to peak velocity of late filling $(A)(E / A)$ ratio $30 \mathrm{~min}$ after ventilation with PEEP. E/A ration of right ventricle was scanned from the 4-chamber view with the sample volume positioned at the tricuspid valvular leaflet tips using pulsed-wave Doppler. RA, right atrium; RV, right ventricle. 


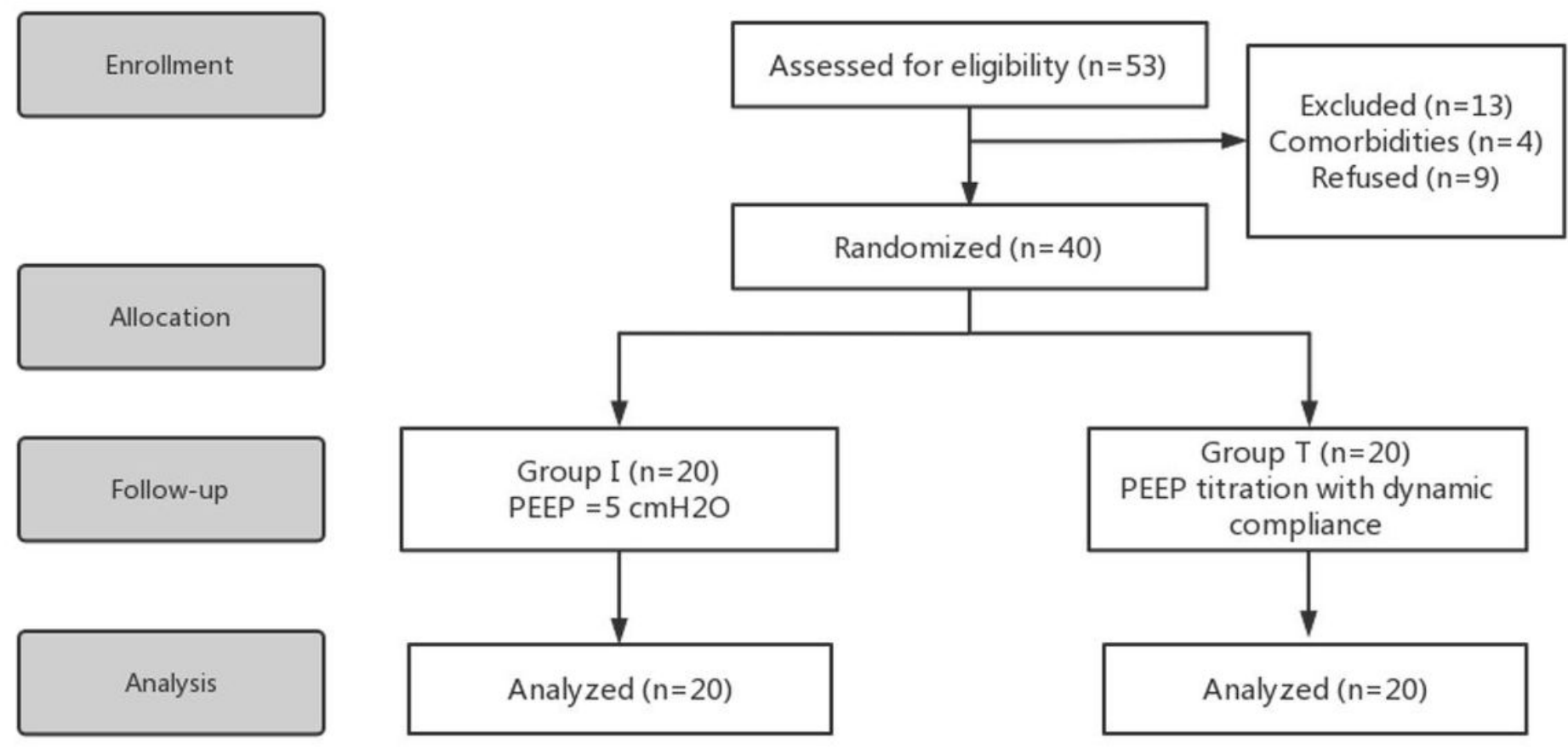

Figure 3

Study flowchart. Group I, control group $\left(P E E P=5 \mathrm{cmH}_{2} \mathrm{O}\right)$; Group $\mathrm{T}$, Cdyn-guided PEEP group. PEEP, positive end-expiratory pressure. 

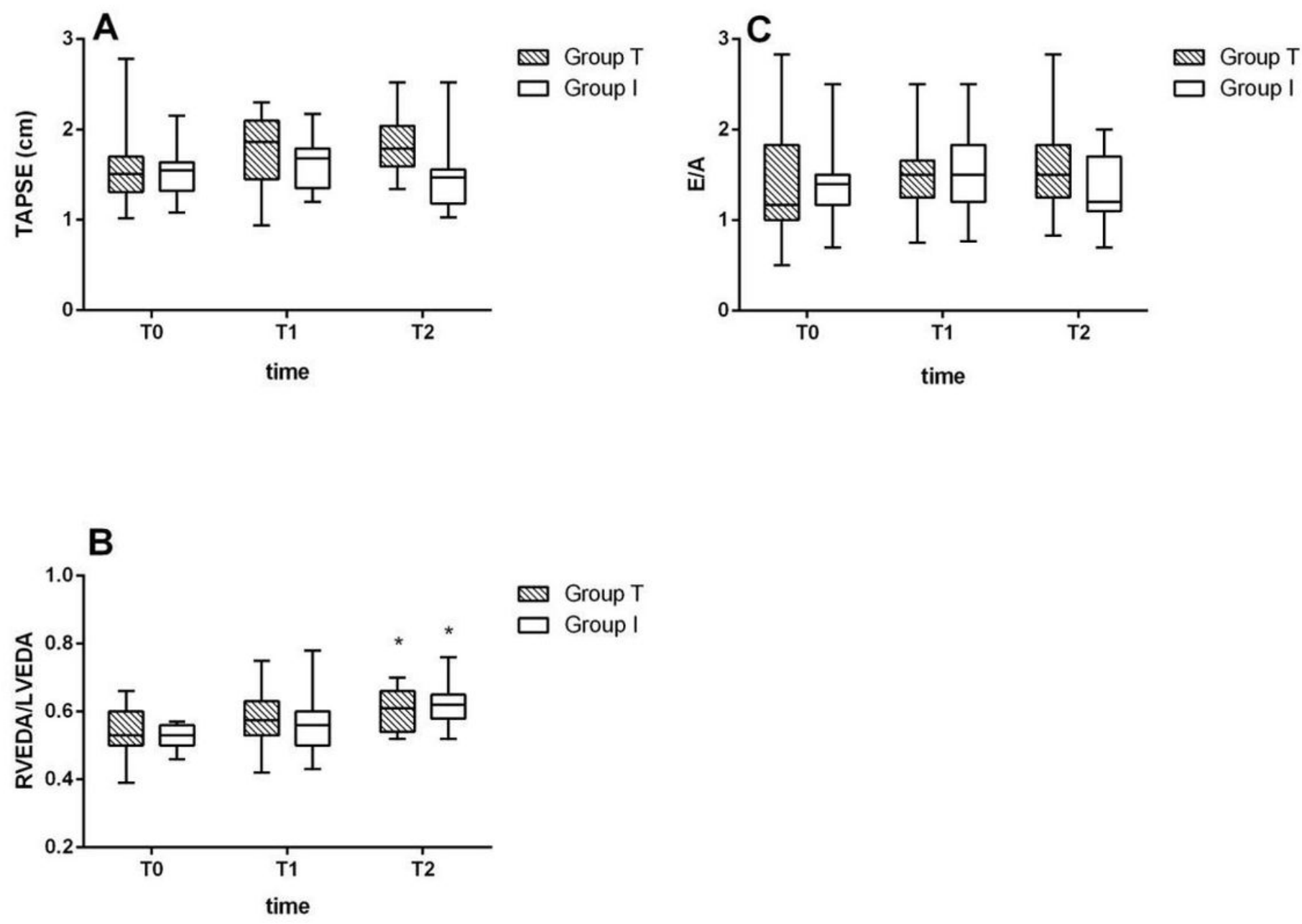

Figure 4

Intraoperative right heart function parameters between groups at T0, T1, and T2. (A) tricuspid annular plane systolic excursion(TAPSE). (B) right ventricular end-diastolic area/left ventricular end-diastolic area(RVEDA/LVEDA) ratio. (C) peak velocity of early filling $(E)$ to peak velocity of late filling $(A)(E / A)$ ratio of right ventricle. Box and whisker plot showing changes between Group I (blank box) and Group T (sloped lined box). The boxes represent the interquartile range, the horizontal line within the boxes represents the median, and whiskers represent $10-90 \%$ error bars. ${ }^{*}, \mathrm{P}<0.05$ as compared to T0 within the group. Group I, control group ( $\left.\mathrm{PEEP}=5 \mathrm{cmH}_{2} \mathrm{O}\right)$; Group T, Cdyn-guided PEEP. T0, $15 \mathrm{~min}$ after intubation; T1, 15 min after pneumoperitoneum and position change; $T 2,30 \mathrm{~min}$ after ventilation with different PEEP. PEEP, positive end-expiratory pressure. 

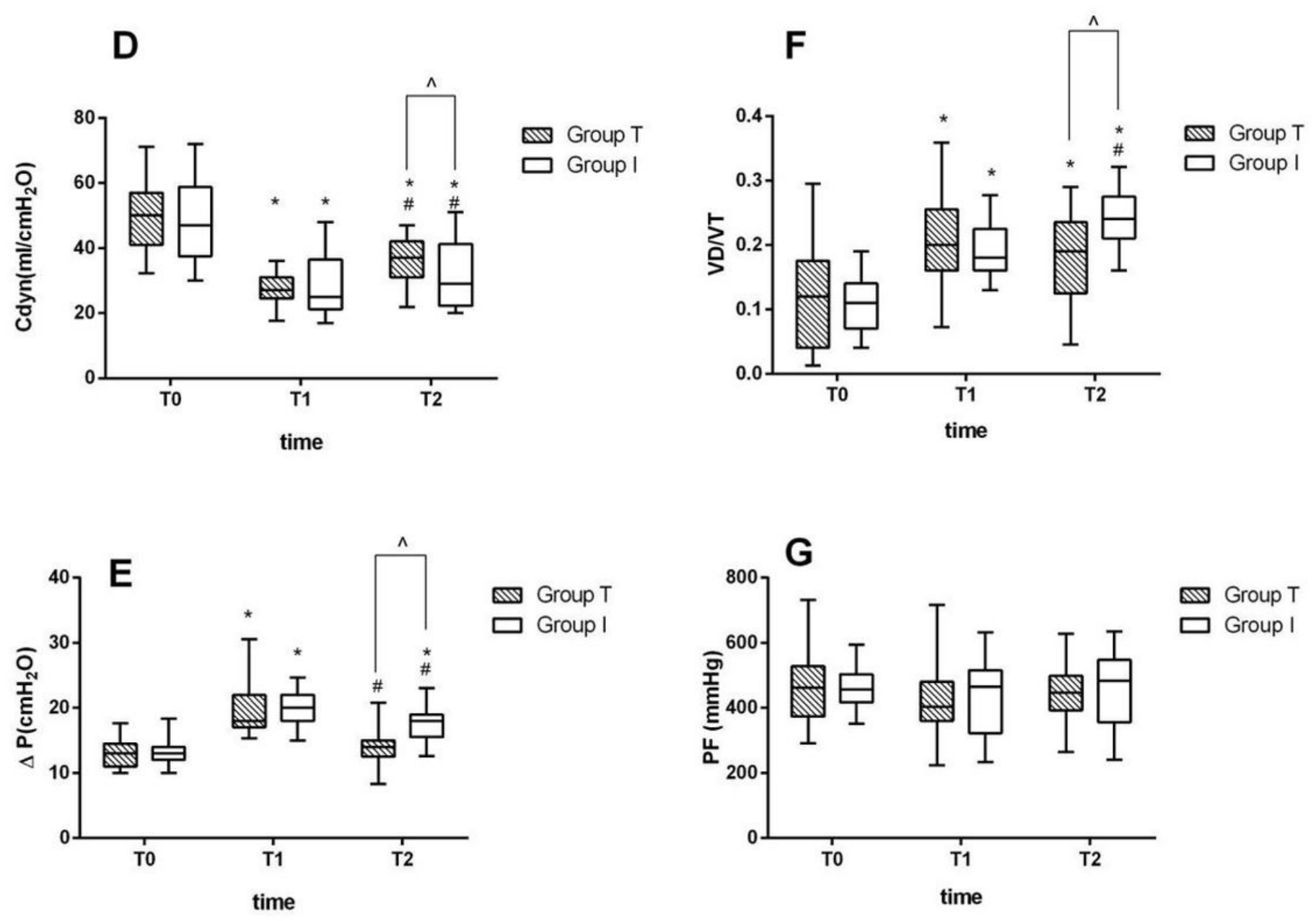

Figure 5

Intraoperative respiratory function parameters between groups at T0, T1, and T2. (D) dynamic compliance(Cdyn). (E) driving pressure $(\Delta P)$. (F) dead space (VD/VT) ratio . (G) partial pressure of arterial oxygen to inspiratory oxygen fraction (PF) ratio. Box and whisker plot showing changes between Group I (blank box) and Group T (sloped lined box). The boxes represent the interquartile range, the horizontal line within the boxes represents the median, and whiskers represent $10-90 \%$ error bars. ${ }^{*}, P<0.05$ as compared to T0 within the group; ${ }^{*}, \mathrm{P}<0.05$ as compared to T1 within the group; ${ }^{\wedge}, \mathrm{P}<0.05$ as compared to Group i at T2. Group i, control group $\left(P E E P=5 \mathrm{cmH}_{2} \mathrm{O}\right)$; Group t, Cdyn-guided PEEP. T0, 15 min after intubation; T1, 15min after pneumoperitoneum and position change; $\mathrm{T} 2,30 \mathrm{~min}$ after ventilation with different PEEP. PEEP, positive end-expiratory pressure. 